\title{
Benefits from Implementing the EPLOS System in Logistics Companies
}

\author{
Emilian Szczepański, Rostislav Vasek, Piotr Klimek, Mariusz Wasiak
}

\begin{abstract}
Logistics companies are currently differently using IT tools to assist the planning of their operational activity. The functionalities of tools are also different. The paper presents the results of a research on the use of automated solutions to obtain the data necessary for logistics processes planning. It also presents a review of IT solutions used by TSL (transport, shipping, logistics) companies and the functionality of these tools. This allowed for the assessment of the potential of the EPLOS system to be used in TSL companies, as well as the benefits of implementing this system. In the paper, the selected results of a survey made in companies about the crucial data needed for efficient operating were presented. The summary indicates the main features that software should have in the era of the Industry 4.0 revolution.
\end{abstract}

Keywords: Big Data Analysis; EPLOS; Industry 4.0; IT for logistic; Logistic 4.0

\section{INTRODUCTION}

Managing logistics processes in today's dynamic economic conditions is very complicated. Depending on the area of actions and the decisions taken, it is necessary to take into account many factors and the specific operating conditions of a system. In the era of the dynamically changing demand, as well as high uncertainty as to the possibility of implementing processes, it is necessary to properly support decision-making processes by using intelligent computer tools and data banks. This applies to the entire industry, i.e. carriers, logistics operators, forwarders, or production plants.

A lot of research is available in literature for the needs of the logistics processes analysis [1-4] and for the purpose of collecting data [5-8]. These tools are often simplified, and the results are subject to a significant error or require a large number of diverse data. In this context, on the one hand, process decision-makers must have appropriate methods and, on the other hand, a proper data bank, which should be dynamically supplemented by contractors and potential contractors. Contemporary technological solutions and the industrial revolution based on the Internet of Things (IoT) or Internet of Vehicle (IoV), as well as the increasingly developed blockchain technologies, big data analysis, and Artificial Intelligence (AI) give the possibility to combine advanced methods with the appropriate data bank, and thus allow an effective support of enterprises in their current operations.

The European Portal of Logistics Services (EPLOS) is a tool based on the latest technological solutions and it is intended to reach a broad audience. It is a portal of logistics services aimed at supporting enterprises' activities in the scope of planning logistics processes by providing reliable data on the logistics infrastructure and services provided by other entities.

Based on the results of the logistics service market research presented in the $\mathrm{PwC}$ report [9], it should be pointed out that transport will be shaped by five main factors. One of them is the constantly growing demand for transport, with the reorganization of transport resulting from the mobility package. An important element are driver shortages, which are estimated at 200,000 in 2020 in Poland. This will require appropriate resource management, because the problem is no longer the shortage of devices and their cost, but the difficulty in filling the workplace [10]. In the context of this paper, the $\mathrm{PwC}$ report touches on digitization, which includes an increase in process automation, including the Internet of things, as well as the industrialization and development of e.g. autonomous vehicles.

This paper presents the EPLOS system in the background of solutions used in logistics companies. The main areas to support decision-makers and the conditions and benefits of its application were indicated. The paper is divided into five parts: Introduction to the topic and its area, A general overview of IT (Information Technology) systems supporting operations in the TSL (Transport, shipping and logistics) industry and the benefits of their use, Characteristics of digital data warehouses as a source of data necessary for the functioning of entities in the logistics industry, Description of the EPLOS system as a response to the needs of companies in the logistics sector resulting from market research. The paper ends with a summary and conclusions from the conducted considerations, systematizing, and directing reflections in the field of modern technologies and support of logistics processes. The paper promotes the sharing and exchange of data in logistics systems and indicates this potential.

\section{IT SYSTEMS AS SUPPORT FOR OPERATIONS IN THE TSL INDUSTRY}

The on-demand economy requires the adaptation of products to customer expectations. The demand for such services, along with the development of technology, is constantly growing and it requires a response from service providers and producers. The logistics, shipping, and transport sector must also adapt to this state of affairs. IT systems have been operating for many years to support the operational activities of enterprises such as ERP (Enterprise Resource Planning), WMS (Warehouse Management system), and TMS (Transport Management System). 
Changes in the market have also resulted in the need for greater integration between enterprises in supply chains, and thus in an improved information flow, which is why SCM (Supply Chain Management) systems have been used more and more often in the previous 20 years [11, 12]. The scope of the systems is presented graphically in Fig. 1.

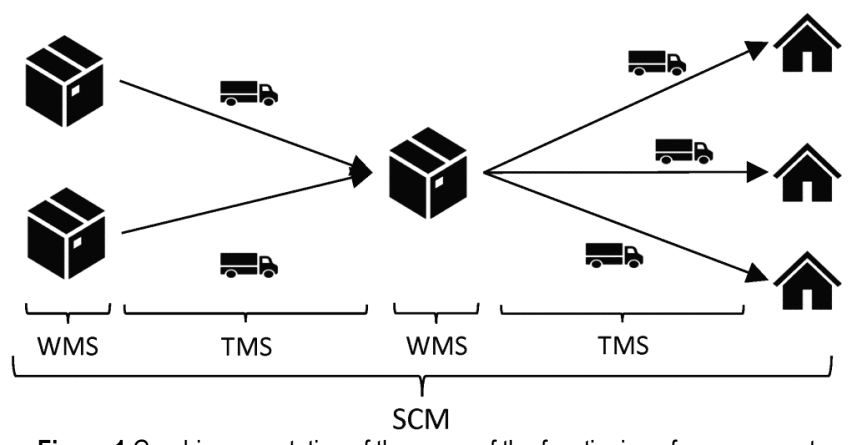

Figure 1 Graphic presentation of the areas of the functioning of management systems in logistics

In transport and forwarding, TMS systems provide the primary support. These are the systems supporting the implementation of transport services through planning and control. They have modules for contractor management, fleet management, order acceptance, route planning, including the optimization of transport performance. TMS supports scheduling, allocation of resources to tasks, and monitoring of transport status. The use of such is dictated by a large number of notifications and resources that must be managed in dynamically changing conditions. These systems allow you to make quick reactions, e.g., in the event of transport complications, cargo problems, or in the buying and planning of orders.

Classic solutions covering the above-mentioned functions are currently not sufficient. Software suppliers are required to be intelligent and intelligently support transport operations. From the beginning of the implementation of such systems and with technological development, but also with the increase in the requirements of customers, their evolution has been taking place. From the classic database approach, TMS is being transformed into a dynamic decision support system, containing many additional modules integrating various areas of transport activity, including economic, legal or ecological [12] activities. Additionally, as the authors indicate [12], in the era of currently prevailing trends, TMS systems are being developed with modules for globally organizing multimodal and intermodal transport.

It is impossible to function effectively without the support of such applications. The new range of functions in TMS requires collecting large amounts of data from various sources. Currently, it is necessary to process large amounts of data, but unfortunately, they are often fragmentary and incomplete, and there are no tools that guarantee the completeness and timeliness of data, especially when they are dispersed in the network. Often, these data are manually searched, entered into the system, and must be manually updated. This is associated with a high risk of error, but also a lot of work.
The term Industry 4.0 is used to refer to the technological developments that occur. The term includes the development and integration of information technologies enabling effective implementation of manufacturing and service processes. It is based on intelligent digital technologies creating cyber-physical systems. This requires adequate communication infrastructure, including data collection, processing, and analysis systems. The term Logistics 4.0 is also associated with this term [13].

Logistics 4.0 is connected with the relationship of services with intelligent tools supporting the activities of employees. This is to prevent uncontrolled situations that may arise and to avoid human errors. It allows for more efficient and faster implementation of individual processes. Therefore, it does not replace human work, but is intended to support its performance and provide the data and analysis to make the right decisions. Including systems in the offered products that take over one part of human work allows you to implement the issue of Smart Logistics. Such activities enable the transferring of the burden to the performance of a more complicated task by man and repetitive, tedious, and often time-consuming activities of intelligent automatic programs. The systems built based on this principle can be used in various areas in logistics, e.g., storage, resource management, vehicle route planning [14]. As it has already been mentioned, effective transport planning requires access to large amounts of data, which often have to be obtained manually. The answer to such needs are "intelligent systems" and infrastructure supporting the flow and collection of information such as the Internet of Things (IoT), Internet of Vehicles (IoV), Internet of Infrastructure (IoI) [15, 16]. Automatic collection and processing of the obtained information, along with the integration with various systems of subcontractors allow for faster and better logistics services.

Planners using information systems integrated with the Internet and other information exchange systems expect fast and accurate analyses regarding the selection of transport offers and the assignment of tasks to vehicles in a way that maximizes the company's revenues, while also keeping in mind sustainable management. Significant support is the equipment of the TMS system with the so-called matching systems that match the enterprise's resources to transport orders [17]. Such mechanisms have been considered for several decades, but only the current state of technology and the possibility of a rapid exchange of information allow their effective application. They allow the analysis of which transport orders to choose for implementation in order to achieve the best possible operational efficiency of the transport company, taking into account customer satisfaction.

\section{DATA WAREHOUSE AND DATA ANALYSIS AS A SOURCE OF INFORMATION FOR ENTITIES IN THE TSL INDUSTRY}

Data in logistics is extremely important for the quality of services rendered. Many factors are responsible for making the right decisions and implementing the process, which must be analysed to predict market changes correctly, manage 
available means of transport, use available infrastructure, and ensure adequate process reliability. In this approach, in the context of the Logistics 4.0 and Smart Logistics paradigm, it is necessary to collect a huge amount of data from many sources. This is related to the issue of Big Data Analysis. This concept, in turn, is associated with data collection and terms such as Data Mining and Data Warehouse. These are the typical terms for the ongoing technological revolution and are also used in logistics. Schematically, this issue in the context of logistics is shown in Fig. 2.

Data such as: digital maps, characteristics of vehicles, customers, insurers, workshops, warehouse facilities, data from GPS (Global Positioning System), RFID (Radio Frequency Identification)

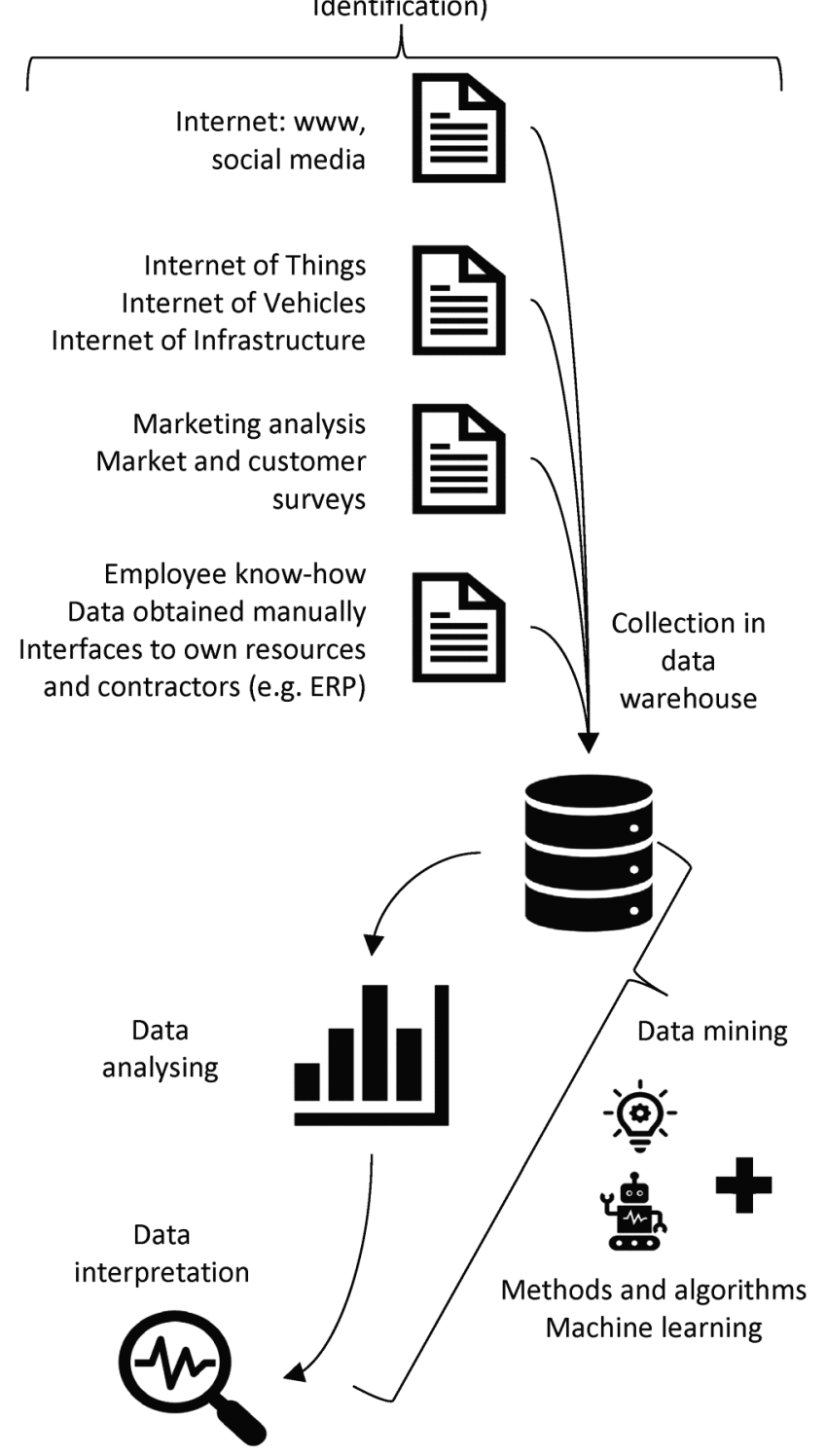

Figure 2 Big Data Analysis in the TSL area

Big Data, as the name suggests, is a collection of a large amount of stored information. It is defined by the $3 \mathrm{~V}$ features: volume, velocity, and variety. Laney introduced such characteristics [18]. Additionally, it can be extended with features such as veracity, value, variability. Generally, it can be said that big data is a collection of a large amount of data, of great diversity, generated and processed at a fast pace, with a certain trust in their correctness, with a specific value for their owner, as well as with a specific use $[19,20]$.

The analysis of data sets that are useful in logistics is a popular topic of scientific research, which is indicated by review works, e.g. [21, 22]. This can be referred to as Supply Chain Analytics (SCA). As shown in Fig. 2, many systems, objects, and distributed information sets can be identified as data sources in the area of logistics. Some of this data can be obtained manually, and some automatically using interfaces. The data comes from their own resources, from individual sensors and receivers, e.g., GPS (Global Positioning System), RFID (Radio Frequency Identification), mobile phones, surveys, and customer satisfaction surveys, order history, etc. In Logistics 4.0, IoT, IoV, IoI is a particularly important data source. This data is cleaned and goes to the Data Warehouse, which is an analytical centre collecting data from various sources. It is only from these data that the useful ones are selected, then they are analysed and interpreted these elements combine into the so-called Data Mining. However, this is not yet SCA, as it needs to be additionally supported by artificial intelligence - machine learning.

The use of the Big Data Analysis in logistics is important for supporting decision making. Investments in new rolling stock, warehouse facilities and concluding contracts are strategic decisions that decide about the company's profitability in the long-term, any changes in the already made decisions are costly and difficult to implement [23]. Therefore, appropriate information resources, along with their analysis and interpretation, are key. These can be various data, e.g. regarding the demand for materials, transport demand, technical or operational data of equipment and infrastructure [24-26]. It is no different when making operational decisions. Of course, their susceptibility to change is much higher, and individual errors do not significantly affect the efficiency of the enterprise, but it is the small decisions that, if accurate, decide on the company's results [27].

\section{EPLOS AS AN SCA SYSTEM AND LOGISTIC PROCESS MANAGEMENT SUPPORT - POTENTIAL BENEFITS}

The EPLOS portal can be described as an SCA (Supply Chain Analytics) tool. It is a tool in which data on the entities on the logistics market, as well as infrastructure, is contained. These data will be collected automatically by using interfaces to the WMS, TMS, ERP systems of enterprises (to the extent in which they agree), as well as entered and supplemented by entities. Users will have access to a wide range of data under the data warehouse. Additionally, the EPLOS system will support them in the analysis of these data and their interpretation, e.g. in the case of the route selection and order for vehicles. The implementation of these functions will be based on the built-in artificial intelligence algorithms.

This system is aimed at supporting the entities and companies operating in the area of the TSL sector. Therefore, it was necessary to analyse the needs of these entities. For the above-mentioned reason, the significance of logistics 
information was identified by using the survey method, as well as an assessment of the present method of data obtaining. Transport, service, production and trade enterprises took part in the survey. Their needs in terms of online information infrastructure, warehouses, logistics centres, and other service facilities needed in the performance of transport were examined. In total, 519 entities were surveyed, of which $28.71 \%$ are logistics service providers, $43.74 \%$ are carriers, i.e., the main recipients of the EPLOS system.

The research results clearly show that despite significant technological progress, including in the field of Big Data, most data are collected manually in transport companies. This applies to smaller enterprises with several dozen employees as well as large transport companies. Among the surveyed entities, over $70 \%$ of the data is collected manually from various sources, including the legal acts, information on the functioning of logistics centres and transhipment points, or transport infrastructure. The percentage share of data collection is shown in Fig. 3.

Manual data acquisition is inefficient and very labourintensive. The time saved can be used for other activities or it can simply reduce the number of employees needed. Thus, the EPLOS system would be an ideal tool to support operations in the TSL industry by collecting and sharing the necessary data.

The analysis of needs indicated that the information on traffic restrictions, road tolls, and services or actual traffic is crucial for the functioning of enterprises. Among the examined entities, the following were considered the key or essential data:

- $\quad$ traffic restrictions $(87.5 \%)$,

- $\quad$ traffic intensity $(86.5 \%)$,

- infrastructure parameters (85.2\%),

- charges for access to infrastructure (84.8\%),

- infrastructure services (81.7\%),

As it should be noted in the case of the TSL sector, infrastructure information is of great importance. With this in mind, the EPLOS system will implement a database containing consistent information and be updated on the road and rail infrastructure on an ongoing basis. The answer to this problem is the use of supported map solutions and their supplementation with the available data from external sources. It was assumed that the EPLOS databases would include road digital maps provided by one of the market leading companies and RailMap railway digital maps offered by OLTIS (the company that is the contractor of the EPLOS project).

Additionally, in the scope of services provided as part of the transport infrastructure for the examined participants of the TSL market, the most important one is information about concentrated parking lots, gas stations, and car washes. The distribution of the validity of these data is shown in Fig. 4. The data regarding these places and services has been included in the EPLOS system to better respond to the needs of potential customers. More complex information about the database used in EPLOS can be found in [28, 29].

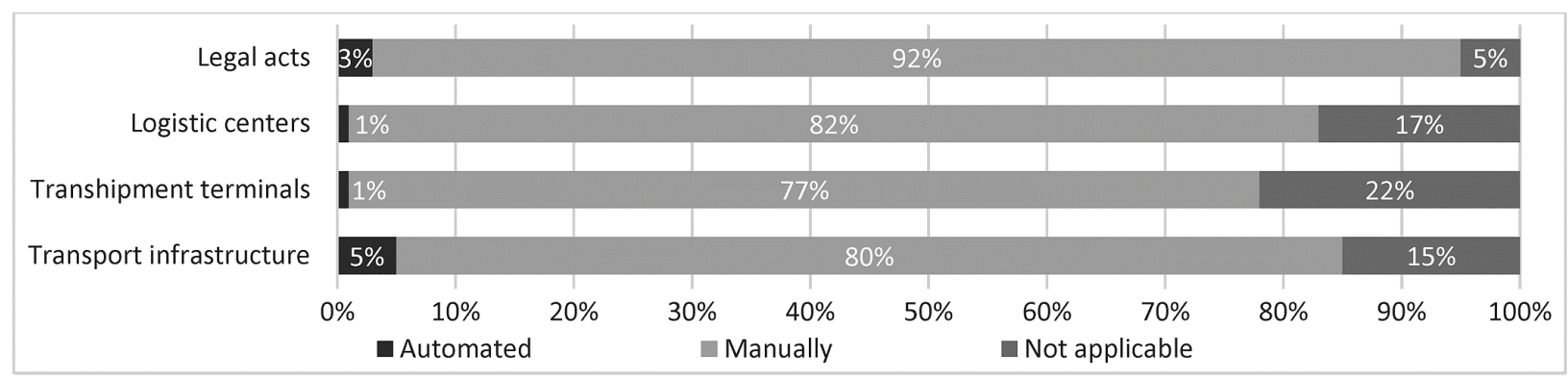

Figure 3 Share of the data collection method in the surveyed entities in TSL

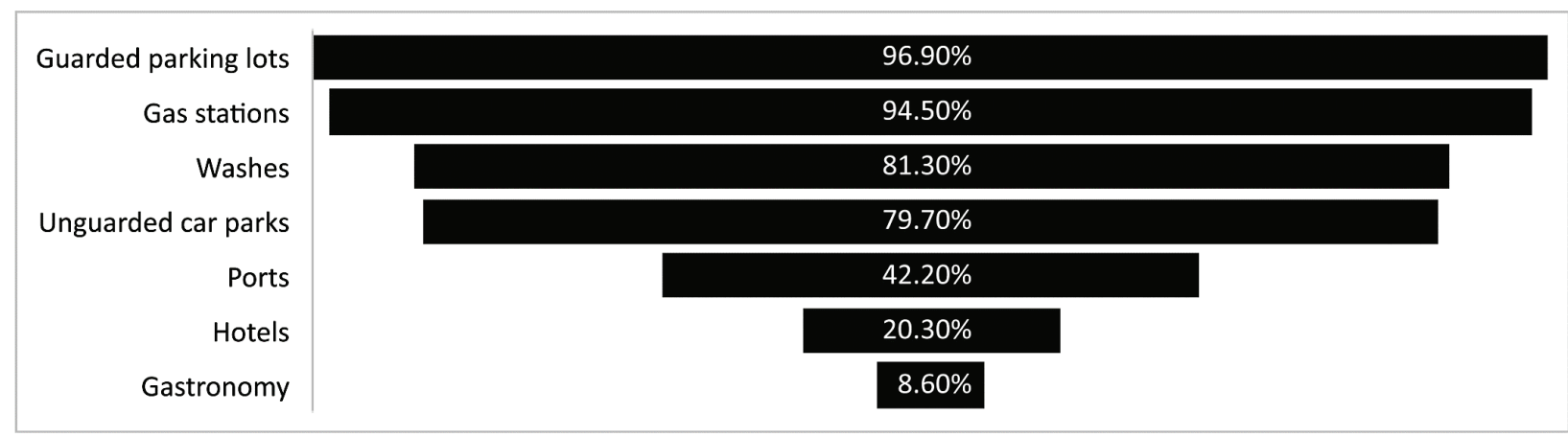

Figure 4 Data identified as key in the scope of additional services by companies from the TSL sector

This system is developed for the specific needs of companies in the TSL industry. Participation in the venture brings many benefits for all participants. In addition to obtaining access to the current data on digital maps and infrastructure, users will share the data enabling the better and faster implementation of processes. These data may relate to basic characteristics such as opening hours, available rolling stock, and number of places in the 
warehouse, but they also may include more sensitive ones. The more data, the more effectively the system will support the activities of cooperating entities.

Basically, the functioning of the system depends on the participation of its users in its creation. Updating data and taking care of their completeness will ensure the full functionality. The chart in Fig. 5 shows the data that enterprises are willing to share within the system. The analysis demonstrates great caution regarding the exchange and sharing of data. Therefore, it will be necessary to encourage entities and show them the benefits that will result in their achievements.

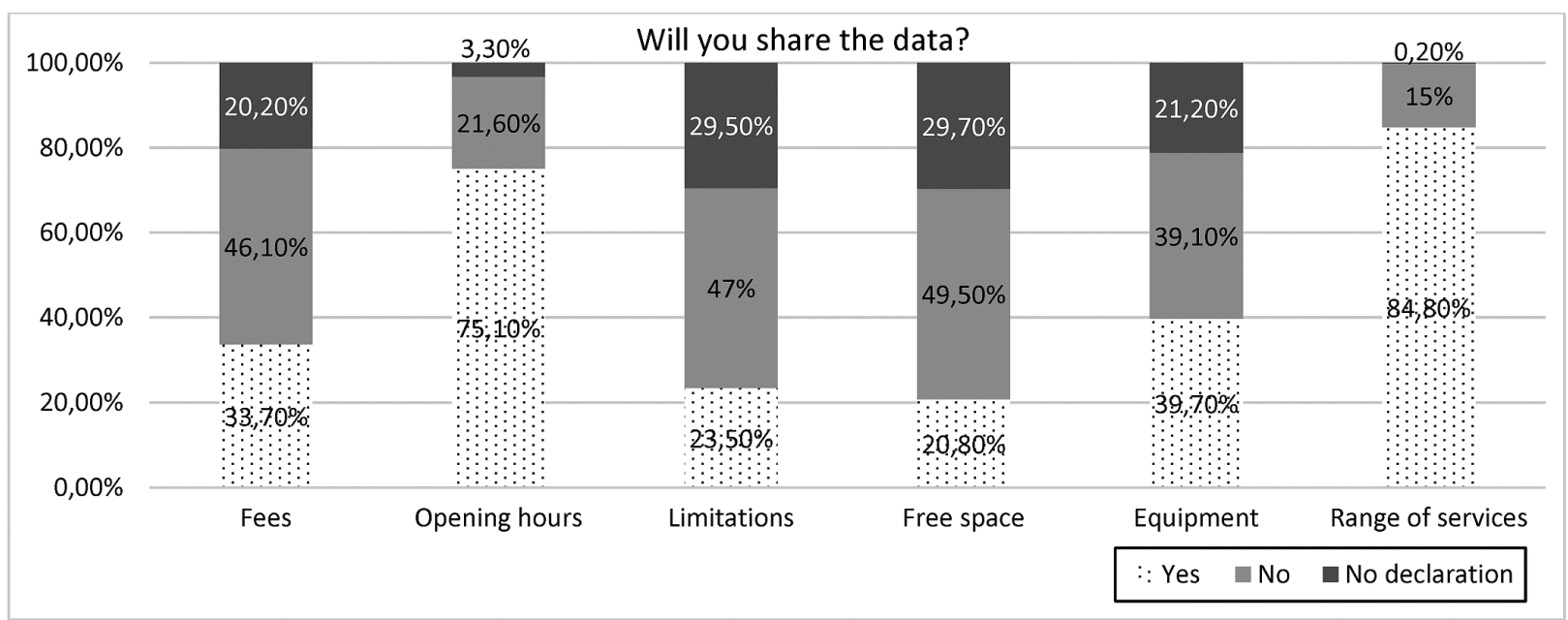

Figure 5 Declaration of data sharing within the EPLOS system

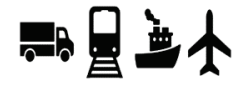

Infrastructure and its technical parameters: road, rail, river, air.

\section{Infrastructure} services: gas stations, lots, hotels car washes, parking

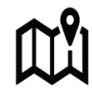

Digital maps including: charges for using the infrastructure, traffic traffic restrictions, current

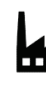

Logistic facilities, provided services, and their parameters: logistics centres, warehouses, transhipment terminals, sidings. Uploading information to a common data warehouse: interfaces, manual

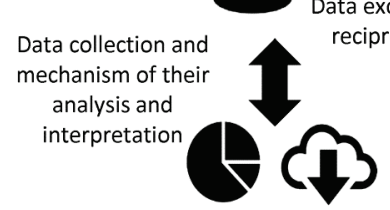

Figure 6 Elements of the EPLOS system

The main benefit of implementing the EPLOS system for logistics companies is the access to regularly updated data on the transport network and business partners. Logistics companies will be able to use the EPLOS databases in a fully automated manner through interfaces. The scope of available data will suit their needs resulting from making decisions in the field of moving goods. They will include data enabling the determination and comparison of options for moving goods, taking into account different types of transport and transshipment terminals. Thanks to the information provided by EPLOS, it will be possible to compare these variants automatically, both for the estimated transport time as well as transport costs. For logistics companies, the EPLOS system will, therefore, expand the functionality of mapping solutions dedicated to truck transport with analogous solutions for rail, air, or inland transport, as well as the information on logistics facilities that is continuously updated. The main functionalities and elements that this system will have are schematically shown in Fig. 6.

Additionally, logistics companies will be able to access reliable and centralized information about potential business partners, as well as compare their offers with the offers of companies with which they currently cooperate. Thus, EPLOS should contribute to improving the competitiveness of logistics service providers, as well as, as a consequence, the competitiveness of logistics companies themselves. This will bring results in the time saved, the better use of resources of individual enterprises, and establishing new contacts. Of course, this will translate into financial savings, social and environmental effects. Therefore, it is a tool that will activate enterprises to share data, enhance integration between entities, and this will be an impulse and a tool for easier creation of supply chains and logistics networks, ensuring data quality and the ability to flow information. The implementation of the EPLOS system in the enterprise is the entrance to a higher level of organization in the context of the Logistics 4.0 paradigm, including the concept of Lean and Agile Management.

The vast potential of using the EPLOS system by logistics companies that implement IT solutions in the field of transport management should also be noted. Namely, these companies will be able to pre-supply local TMS databases with information about their business partners obtained from the EPLOS system. More importantly, thanks to the use of the EPLOS system, this information will be updated regularly. It allows for substantial savings for logistics companies resulting from a significant reduction of the manual acquisition of a lot of data. Thus, enterprises will be able to engage employees for other operational activities and thus achieve additional revenues. At the same time, enterprises will obtain a guarantee of correctness and 
timeliness of data, as well as become more competitive on the market.

\section{CONCLUSIONS}

The dynamics of market changes, customer needs, and the strategy of operation forces entities in the TSL sector to adapt to prevailing trends. The Industry 4.0 paradigm and the related Logistics 4.0 , as well as the possibilities of using the Internet of Things, allow companies to implement new solutions that respond to current market needs. Nowadays, it is access to data and the ability to analyse and interpret it, which is particularly valuable and, at the same time, necessary for the effective provision of services. Data obtained independently without coordination are often dispersed, their usefulness is disputable, and the labour consumption of obtaining is high.

As the authors indicate [12], systems supporting the operation of logistics enterprises must meet a number of requirements. The main ones include: increasing interoperability - facilitating document exchange, data flow, interfaces for data exchange; providing a tool that will provide certain data along with their analysis and interpretation - this will enable the development of various scenarios and thus increase the resistance to interference and downtime; better process planning and control implementation of more sophisticated algorithms supporting decision making, resulting in higher efficiency, punctuality and the reliability of processes. Moreover, the system must meet a number of technological requirements such as the ease of use, low cost of use, flexibility, the ability to adapt to individual needs.

The EPLOS system is, therefore, the answer to today's challenges and support in the acquisition and use of data. It will provide entities with data concentrated in one place, easily accessible, current, and standardized. Furthermore, it will enable the use of implemented tools for their interpretation. The success of the venture, however, depends on the way companies think and whether they want to integrate and exchange data.

On the one hand, the EPLOS system must be a tool containing the basic data and the data on the services of other entities. On the other hand, this tool must encourage the exchange of data and promote those who are willing to share data. Only such an approach guarantees the success and usability of this system and, at the same time, a response to the challenges posed by today's market.

\section{Acknowledgements}

This study is the result of work carried out as part of the EPLOS (European Portal of Logistics Services) project under the EUREKA initiative funded by the Polish National Centre for Research and Development.

\section{Notice}

The paper will be presented at MOTSP 2020 International Conference Management of Technology - Step to Sustainable Production, which will take place from $30^{\text {th }}$
September $-2^{\text {nd }}$ October 2020 in Bol, island Brač (Croatia). The paper will not be published anywhere else.

\section{REFERENCES}

[1] Jacyna-Gołda, I., Kłodawski, M., Lewczuk, K., Łajszczak, M., Chojnacki, T., \& Siedlecka-Wójcikowska, T. (2019). Elements of perfect order rate research in logistics chains. Archives of Transport, 49(1), 25-35.

https://doi.org/10.5604/01.3001.0013.2771

[2] Kłodawski, M., Jachimowski, R., Jacyna-Gołda, I., \& Izdebski, M. (2018). Simulation Analysis of Order Picking Efficiency with Congestion Situations. International Journal of Simulation Modelling, 17(3), 431-443. https://doi.org/10.2507//JSIMM17(3)438

[3] Świderski, A., Jóżwiak, A., \& Jachimowski, R. (2018). Operational quality measures of vehicles applied for the transport services evaluation using artificial neural networks. Eksploatacja i Niezawodność, 20(2), 292-299. https://doi.org/10.17531/ein.2018.2.16

[4] Wasiak, M., Jacyna-Gołda, I., Markowska, K., Jachimowski, R., Kłodawski, M., \& Izdebski, M. (2019). The use of a supply chain configuration model to assess the reliability of logistics processes. Eksploatacja i Niezawodność, 21(3), 367-374. https://doi.org/10.17531/ein.2019.3.2

[5] Jachimowski, R., Gołębiowski, P., Izdebski, M., Pyza, D., \& Szczepański, E. (2017). Designing and efficiency of database for simulation of processes in systems. Case study for the simulation of warehouse processes. Archives of Transport, 41(1), 31-42. https://doi.org/10.5604/01.3001.0009.7380

[6] Jacyna, M., Gołębiowski, P., Szczepański, E., \& Wasiak, M. (2017). Efficacy of Data Security in Managing the Database of SIMMAG 3D System. Procedia Engineering, 187, 526-531. https://doi.org/10.1016/j.proeng.2017.04.410

[7] Tang, Y., \& Zhang, W. (2016). Computer-aided model construction and database design of railway yard information. Archives of Transport, 38(2), 71-78, https://doi.org/10.5604/08669546.1218799

[8] Żak, J., Jachimowski, R., Gołębiowski, P., \& Szczepański, E. (2016). Relational character of the data in the context of functional modules of the system SIMMAG 3D. W: CLC, 700705.

[9] PWC (2019). Transport of the future. Reports on prospects for the development of road transport in Poland in 2020-2030. (Available online on: https://tlp.org.pl/)

[10] Rudyk, T., Szczepański, E., \& Jacyna., M. (2019). Safety factor in the sustainable fleet management model. Archives of Transport, 49(1), 103-114. https://doi.org/10.5604/01.3001.0013.2780

[11] Barreto, L., Amaral, A., \& Pereira, T. (2017). Industry 4.0 implications in logistics: an overview. Procedia Manufacturing, 13, 1245-1252. https://doi.org/10.1016/j.promfg.2017.09.045

[12] Nettsträter A., Geißen T., Witthaut M., Ebel D., \& Schoneboom J. (2015) Logistics Software Systems and Functions: An Overview of ERP, WMS, TMS and SCM Systems. In: ten Hompel M., Rehof J., Wolf O. (eds) Cloud Computing for Logistics. Lecture Notes in Logistics. Springer, Cham. https://doi.org/10.1007/978-3-319-13404-8_1

[13] Anderl, R. (2014, October). Industrie 4.0-advanced engineering of smart products and smart production. In Proceedings of international seminar on high technology (Vol. 19).

[14] Uckelmann, D. (2008, September). A definition approach to smart logistics. In International Conference on Next 
Generation Wired/Wireless Networking (pp. 273-284). Springer, Berlin, Heidelberg. https://doi.org/10.1007/978-3-540-85500-2_28

[15] Cai, Y. (2019). Analysis on the Status Quo of "Internet+ Logistics" Enterprises Matching Vehicle and Cargo.

[16] Macaulay, J., Buckalew, L., \& Chung, G. (2015). Internet of things in logistics: A collaborative report by DHL and Cisco on implications and use cases for the logistics industry. DHL Trend Research and Cisco Consulting Services.

[17] Janssen, M. \& Verbraeck, A. (2008). Comparing the strengths and weaknesses of Internet-based matching mechanisms for the transport market. Transportation Research Part E: Logistics and Transportation Review, 44(3), 475-490. https://doi.org/10.1016/j.tre.2006.11.002

[18] Laney, D. (2001). 3D Data management: Controlling data volume, velocity and variety. Meta Group.

[19] Borgi, T., Zoghlami, N., \& Abed, M. (2017, January). Big data for transport and logistics: A review. In 2017 International Conference on Advanced Systems and Electric Technologies (IC ASET) (pp. 44-49). IEEE. https://doi.org/10.1109/ASET.2017.7983742

[20] Chen, M., Mao, S., \& Liu, Y. (2014). Big data: A survey. Mobile networks and applications, 19(2), 171-209. https://doi.org/10.1007/s11036-013-0489-0

[21] Govindan, K., Cheng, T. C. E., Mishra, N., \& Shukla, N. (2018). Big data analytics and application for logistics and supply chain management. Transportation Research Part E: Logistics and Transportation Review, 114, 343-349. https://doi.org/10.1016/j.tre.2018.03.011

[22] Wang, G., Gunasekaran, A., Ngai, E. W., \& Papadopoulos, T. (2016). Big data analytics in logistics and supply chain management: Certain investigations for research and applications. International Journal of Production Economics, 176, 98-110. https://doi.org/10.1016/j.ijpe.2016.03.014

[23] Jacyna-Gołda, I., Izdebski, M., Szczepański, E., \& Gołda, P. (2018). The assessment of supply chain effectiveness. Archives of Transport, 45(1), 43-52. http://doi.org/10.5604/01.3001.0012.0966

[24] Kukulski, J., Gołębiowski, P., Pyza, D., Jachimowski, R., \& Wychowański, W. (2019). Selected aspects of the selection of data sent to the vehicle in automatic rail vehicle driving systems. Scientific Journal of Silesian University of Technology. Series Transport, 103, 43-52. https://doi.org/10.20858/sjsutst.2019.103.4.

[25] Kukulski, J., Jacyna, M., \& Gołębiowski, P. (2019). Finite Element Method in Assessing Strength Properties of a Railway Surface and Its Elements. Symmetry-Basel, 8(11), 1-29. https://doi.org/10.3390/sym11081014

[26] Świderski, A., Borucka, A., Jacyna-Gołda, I., \& Szczepański, E. (2019). Wear of brake system components in various operating conditions of vehicle in the transport company. Eksploatacja i Niezawodność, 21(1), 1-9. https://doi.org/10.17531/ein.2019.1.1

[27] Jacyna, M., Izdebski, M., Szczepański, E., \& Gołda, P. (2018). The task assignment of vehicles for a production company. Symmetry-Basel, 11(10), 1-19. https://doi.org/10.3390/sym10110551

[28] Jacyna, M., Wasiak, M., Jachimowski, R., Gołębiowski, P., Klimek, P., Vasek, R., Jacyna-Gołda, I., \& Izdebski, M., (2019). The Concept of EPOS Database of the Transport Infrastructure. $23^{\text {rd }}$ international scientific conference Transport Means 2019 Sustainability: Research and Solutions Proceedings $23^{\text {rd }}$ International Scientific Conference / Kersys Robertas (ed.), Transport Means, 1250-1255.
[29] Wasiak, M., Lewczuk, K., Jachimowski, R., Kłodawski, M., Jacyna-Gołda, I., Izdebski, M., Klimek, P., \& Vasek, R., (2019). Concept of EPLOS database of logistics facilities. $23^{\text {rd }}$ international scientific conference Transport Means 2019 Sustainability: Research and Solutions Proceedings $23^{\text {rd }}$ International Scientific Conference / Kersys Robertas (ed.), Transport Means, 1317-1322.

\author{
Authors' contacts: \\ Emilian Szczepański, Associate Professor, PhD (Eng,) \\ (Corresponding author) \\ Faculty of Transport, Warsaw University of Technology, \\ Koszykowa 75, room 367, 00-662 Warsaw, Poland \\ eszczepanski@wt.pw.edu.pl \\ Rostislav Vasek \\ CID International, a.s. \\ OLTIS Group a.s. \\ Dr. Milady Horakove 1200/27a, 77900 Olomouc, Czech Republic \\ Koszykowa 75, room 366, 00-662 Warsaw, Poland \\ rvasek@cid.cz
}

\section{Piotr Klimek}

OLTIS Polska Sp. z o. o.

Króla Kazimierza Wielkiego 21/203A,

32-300 Olkusz, Poland

info@oltis.pl; www.oltis.pl

Mariusz Wasiak, Associate Professor, PhD (Eng.)

Faculty of Transport, Warsaw University of Technology,

Koszykowa 75, room 363, 00-662 Warsaw, Poland

mwa@wt.pw.edu.pl 